\title{
Smart technology for healthcare: Exploring the antecedents of adoption intention of healthcare wearable technology
}

\author{
Ka Yin Chau, ${ }^{1}$ Michael Huen Sum Lam, ${ }^{2}$ Man Lai Cheung, ${ }^{3}$ Ejoe Kar Ho Tso, ${ }^{4}$ \\ Stuart W. Flint, ${ }^{5}$ David R. Broom, ${ }^{6}$ Gary Tse, ${ }^{7}$ Ka Yiu Lee ${ }^{8}$ \\ ${ }^{1}$ Faculty of International Tourism and Management, City University of Macau, Macau; ${ }^{2}$ Faculty of \\ Health and Wellbeing, Sheffield Hallam University, UK; ${ }^{3} B N U-H K B U$ United International College, \\ China; ${ }^{4}$ Borneo Business School, North Borneo University College, Kota Kinabalu, Malaysia; \\ ${ }^{5}$ School of Sport, Leeds Beckett University, UK; ${ }^{6}$ Academy of Sport and Physical Activity, \\ Sheffield Hallam University, UK; ${ }^{7}$ Lee Ka Shing Institute of Health Sciences, Chinese University of \\ Hong Kong, Hong Kong; ${ }^{8}$ Faculty of Health and Wellbeing, Sheffield Hallam University, UK
}

\begin{abstract}
Technological advancement and personalized health information has led to an increase in people using and responding to wearable technology in the last decade. These changes are often perceived to be beneficial, providing greater information and insights about health for users, organizations and healthcare and government. However, to date, understanding the antecedents of its adoption is limited. Seeking to address this gap, this cross-sectional study examined what factors influence users' adoption intention of healthcare wearable technology. We used self-administrated online survey to explore adoption intentions of healthcare wearable devices in 171 adults residing in Hong Kong. We analyzed the data by Partial least squares - structural equation modelling (PLS-SEM). The results reveal that perceived convenience and perceived irreplaceability are key predictors of perceived useful-
\end{abstract}

\footnotetext{
Correspondence: Man Lai Cheung, Beijing Normal University-Hong Kong Baptist University, United International College, 2000 Jintong Road, Tangjiawan, Zhuhai, China.

E-mail: manlaiicheung@gmail.com

Key words: Healthcare wearable technology; Adoption intention, technical attributes, perceived Hong Kong.

Contributions: KYC and MLC developed the conceptual model of this study. MLC and MHSL developed the questionnaire. KYC, MHSL and EKHT recruited participants. MLC undertook the data analysis. KYC, MHSL, KYL and GT checked the data analysis. SWF and DRB checked the grammatical mistakes. All authors wrote and approved a final version of the manuscript.

Conflict of interest: the authors declare no potential conflict of interest.

Funding: none.

Received for publication: 7 February 2019

Accepted for publication: 11 March 2019.

This work is licensed under a Creative Commons AttributionNonCommercial 4.0 International License (CC BY-NC 4.0).

(C) Copyright: the Author(s), 2019

Licensee PAGEPress, Italy

Health Psychology Research 2019: 7:8099

doi:10.4081/hpr.2019.8099
}

ness, which in turn strengthens users' adoption intention. Additionally, the results also reveal that health belief is one of the key predictors of adoption intention. This paper contributes to the extant literature by providing understanding of how to strengthen users' intention to adopt healthcare wearable technology. This includes the strengthening of perceived convenience and perceived irreplaceability to enhance the perceived usefulness, incorporating the extensive communication in the area of healthcare messages, which is useful in strengthening consumers' adoption intention in healthcare wearable technology.

\section{Introduction}

With the technological advancement of information technology, developers have improved the applicability of technological devices in various contexts (Due, 2014; Kim \& Shin, 2015; Lee et al., 2016), including education (Knight et al., 2015), healthcare (Signorini et al., 2014) and sport (Choi \& Kim, 2016). One such advancement is the development of healthcare wearable technology, which is useful in promoting sports and physical activities and in doing so, benefiting health (Zhang et al., 2017). Generally, healthcare wearable technology is understood as an electronic technology which is incorporated into accessories that can be worn on the users' body (Tehrani \& Michael, 2014), such as Google Glass, iWatch, Fitbit and Mi Band wristband, which have been applied in the healthcare and medical industries (Chan et al., 2012; Zhang et al., 2017). The healthcare wearable technology market is expected to more than double in the next five years (MedTech Impact of Wellness, 2018), and is estimated to be worth 58.3 billion dollars by 2025 (HealthWorks Collective, 2018), thus, being regarded as one of the most important technologies in the future, in terms of improving healthcare efficiency and reducing healthcare cost (Li et al., 2016).

Combining technological attributes with health attributes, healthcare wearable technology products are useful in tracking information about the health of users in real-time (Chan et al., 2012). For example, using wristbands, users can monitor their health conditions in real-time, including sleeping conditions, heart rate as well as distance travelled, giving the reference for users to initiate activities to improve their health by analyzing and managing their real-time data (Li et al., 2016).

Despite these promising developments, empirical studies exploring the antecedents of healthcare wearable technology adoption is scant. Seeking to address the aforementioned gaps, the 
purpose of this study was to gain knowledge in this area and provide meaningful managerial implications for practitioners and wearable device developers. The remainder of this paper is organized as follows. First, we review the relevant literature to identify the research gaps. Second, we present a theoretical model underpinning association between constructs of Technology Acceptance Model (TAM) and health belief, where perceived convenience, perceived credibility, irreplaceability acts as drivers of perceived usefulness, incorporating the links between perceived health and adoption intention of healthcare wearable technology. Third, we describe the research methodology and results of data analysis. Finally, we discuss the theoretical and managerial implications, along with limitations and directions for future research.

\section{Technology acceptance model (TAM)}

Widely acknowledged as one of the most influential theoretical models in Information System discipline, the TAM was introduced by Davis (1989) to examine the antecedents of users' adoption intention of information communication technology (Legris, Ingham \& Collerette, 2003; Ooi \& Tan, 2016; Wu \& Chen, 2017). The TAM model posits that perceived ease of use and perceived usefulness are influential factors in determining users' adoption intention (Davis, 1989), being applied in various contexts since then such as online banking (Pikkarainen et al., 2004), mobile commerce (Wu \& Wang, 2005), healthcare (Holden \& Karsh, 2010; Pai \& Huang, 2011), sports websites (Hur, Ko \& Claussen, 2012), social networking sites (Choi \& Chung, 2013) and healthcare wearable technology (Gao, Li \& Luo, 2015). Although there is some criticism of the TAM (Bagozzi, 2007; Benbasat \& Barki, 2007; Read, Robertson \& McQuilken, 2011), it is generally acknowledged as one of the most preferable theoretical models in explaining users' adoption intention of information technology (Chuah et al., 2016). Therefore, we adopted TAM as one of our fundamental theories to formulate constructs in this study.

\section{Health belief model (HBM)}

The HBM explains the behavioral responses of individuals with diseases to treatment received (Champion \& Skinner, 2008), and is applied to guide health behavior interventions (Ross et al., 2010). In particular, HBM posits that people's perceived susceptibility, severity, benefits and barriers are predictors of their healthrelated behavior (Zhang et al., 2018). Given its importance in predicting behavioral intention toward healthcare related products (Ahlan \& Ahmad, 2014; Gao et al., 2015; Indu \& Jagathy Raj, 2012), we adopted HBM as one of our fundamental theories in this study to derive a relatively new construct, namely, perceived health belief, as a predictor of the adoption intention of healthcare wearable technology.

\section{Theoretical framework and hypotheses develop- ment}

\section{Perceived usefulness}

Perceived usefulness refers to the degree to which an individual believes that using a particular system would enhance his or her job performance (Davis, 1989), being understood as one of the most influential drivers in determining users' information technology usage intention (Chuah et al., 2016). Arguably, when the information technology product is perceived to be beneficial, creating external rewards to users, such positive expectation in outcomes creates extrinsic motivation, which in turn strengthens intention to use a product (Kim, Chan \& Gupta, 2007). Similarly, when consumers believe that healthcare wearable technology is useful in enhancing their health status, their positive expectation strengthens their intention to use healthcare wearable technology, such as healthcare applications, smart glasses and smart watches (Kalantari, 2017; Kim \& Shin, 2015; Wang et al., 2014). Thus, aligned with prior research in the area of healthcare wearable technology, it is logical to postulate that perceived usefulness is positively linked with users' adoption intention, justifying the following hypothesis:

H1: Perceived usefulness is positively associated with adoption intention of healthcare wearable technology.

\section{Perceived convenience}

Perceived convenience refers to consumers' perceptions of convenience toward time, place and execution that consumers feel during the process of using a product. This is measured by perceived time and efforts to be spent on a product, which is similar to "ease of use" in the TAM model (Berry et al., 2002; Yoon \& Kim, 2007). Applied to a healthcare wearable technology context, consumers' perceived convenience is more positive when it can be used at any time, in any place and can use the product easily (Zhang et al., 2017).

As expected, there are positive links between perceived convenience and perceived usefulness, where products are perceived to be more useful when they are perceived to be convenient in improving health and living, hence stimulating users' intention to use (Nasir \& Yurder, 2015; Yoon \& Kim, 2007). For example, when healthcare wearable technology can be used easily at any time and in any place, its convenience provides benefits to consumers in improving their health condition with more effective ways, being perceived to be more useful in terms of improving healthcare efficiency (Li et al., 2016; Zhang et al., 2017). Thus, we hypothesized:

$\mathrm{H} 2$ : Perceived convenience is positively associated with perceived usefulness of healthcare wearable technology.

\section{Perceived irreplaceability}

Conceptualized as symbolic meaning, perceived irreplaceability occurs when a product has specific symbolic meaning to an individual that is not exist in other products (Schifferstein \& Zwartkruis-Pelgrim, 2008). Arguably, when a product is regarded as irreplaceable, consumers' continuous usage is expected because of psychological dependence (Wang et al., 2015). In other words, consumers refuse to switch the products or services with another that holds less significance. This is reflects an enjoyment of the benefits obtained from a product and desire to retain it for as long as possible (Gong et al., 2019). Applied to a healthcare wearable technology context, when consumers believe that healthcare wearable device is irreplaceable in their life, they have a strong product attachment. This can also lead to a strong sense of brand loyalty (Pedeliento et al., 2016). Therefore, it is logical to propose the link between perceived irreplaceability and perceived usefulness of healthcare wearable technology, justifying the following hypothesis:

H3: Perceived irreplaceability is positively associated with perceived usefulness of healthcare wearable technology. 


\section{Perceived credibility}

Perceived credibility has inextricable relationship with trustworthiness and expertise, indicating the extent to which one believes that the information technology is reliable in finishing required tasks effectively (Ayeh, 2015; Featherman, Miyazaki \& Sprott, 2010; Shin, Lee \& Hwang, 2017). Prior studies (e.g., Wang et al., 2003) have integrated perceived credibility in various contexts including online banking, mobile banking (Zhou, Lu \& Wang, 2010) and mobile wallets (Shin, 2009). These studies report that perceived credibility strengthens users' acceptance of information technology products and services (Shaw, 2014; Shin, Lee \& Hwang, 2017; Ukpabi \& Karjaluoto, 2017). For the information technology industry, perceived credibility is determined by users' privacy and security concerns (Wang et al., 2003). In particular, perceived credibility is formulated by consumers' perceived level of security and privacy, the former, refers to the protection of information from unauthorized outflows, and the latter refers to the protection of data that are collected during users' interactions with the specific information systems (Ariff et al., 2013).

Applied to the context of healthcare wearable technology, perceived credibility is formulated by perceived privacy protection and perceived technology accuracy (Zhang et al., 2017). Perceived privacy protection is an important consideration for healthcare wearable technology adoption because users must input their personal data about their health status to obtain valuable services. Thus, users require protection of these personalized information from unauthorized outflows (Zhang et al., 2017).Perceived technology accuracy is also particularly important in affecting the perceived credibility of healthcare wearable technology because the accuracy of users' health data is useful in evaluating users' health status and effectiveness of sports exercises (Korenkova \& Hägerfors, 2011; Metzger et al., 2003). Summing up, privacy protection formulates users' perceived technology accuracy as well as perceived credibility, which is postulated to be positively associated with perceived usefulness (Kawakami \& Parry, 2013). Thus, we hypothesized:

H4: Perceived credibility of healthcare wearable technology positively impact its perceived usefulness.

\section{Health belief}

In the last ten years, individuals are paying more attention on healthcare, attracting developers' interest in developing technological products for the healthcare sector, which in turn has created diversified healthcare wearable technology products in the market for the general public, such as smartwatches, Fitbit Flex and Mi Band wristband (Chuah et al., 2016). Indeed, one of the most valuable functions of these healthcare wearable technology products is the provision of users' health data, assisting users to check their health status as well as planning their exercises (Zhang et al., 2017). Therefore, it is not surprising that empirical studies examine the links between users' health belief and their intention to use by integrating health belief in the TAM model, and thereby confirming the role of health belief in strengthening consumers' intention to use wearable technology products (Özkan et al., 2012; Zhang et al., 2017). The literature presented above justifies the recognition of health belief as a relevant construct in the theoretical model in this study. Thus, we hypothesized:

H5: Health belief positively impacts the adoption intention of healthcare wearable technology.

\section{Research methodology}

\section{Development of measurement items}

To test the aforementioned hypotheses in the theoretical model, we used a self-administered online survey (English language) to collect data from a convenience sample of consumers in Hong Kong. We used measurement items adopted from previous studies to develop the survey questionnaire (Table 1), measured on a 7point Likert scales $(1=$ strongly disagree, $2=$ disagree, $3=$ somewhat disagree, $4=$ neither agree or disagree, $5=$ somewhat agree, $6=$ agree, 7 = strongly agree)

\section{Data collection}

The survey was promoted using a convenience sampling approach by e-mail to contacts and promoted on social media in Hong Kong by the research team. Data collection took place from October 1st 2018, to January 5th 2019) a total of 14 weeks. To ensure the validity of our study, we designed several screening questions to assess the accuracy of respondent's knowledge of healthcare wearable technology. The screening questions include: "Have you ever bought a healthcare wearable technology product?", "Have you ever used wearable technology product?" and "Have you ever read product reviews about healthcare wearable technology products on website/ social media platforms/ blogs / forums?". Respondents without experience of healthcare wearable technology were excluded from the current study. After exclusion, a total of 310 consumers were invited to participate in the survey. In total, 237 completed the survey. Sixty-six participants were discarded due to incomplete responses, resulting in a final sample of 171 participants; $55.2 \%$ response rate. Respondents were over 18 years old and users of healthcare wearable technology products. The sample comprised 55\% male (45\% female) respondents, with ages ranging from 18 to 65 (mean $=26-30$ years) and a large proportion aged between 22 and $26(36.3 \%)$. Most respondents were university educated $(50.9 \%)$, with experience in using healthcare wearable technology products and a large proportion owned more than 3 healthcare wearable technology products $(49.7 \%)$.

\section{Data analysis and results}

\section{Data analysis}

In this study, we used partial least squares-structural equation modelling (PLS-SEM) for data analysis, using SmartPLS v3.28 (Ringle et al., 2015) with the 5,000-bootstrap procedure to assess the (1) measurement (outer) model and (2) structural (inner) model. Hypotheses are considered to be significant if $p \leq .05$ or marginally accepted if $p \leq .10$.

\section{Measurement model}

For the measurement model (Figure 1), we tested the reliability of the measurement items by checking their factor loadings, Cronbach's alpha and composite reliability (CR). As presented in Table 1, the loadings of all items were greater than .833 and significant, whereas Cronbach's alpha and CR of all of the constructs were greater than .874 , which is well above the recommended .70 thresholds, confirming the reliability of the measurement items and constructs. Additionally, as presented in Table 2, we tested the convergent validity of the model by using Average Variance Extracted (AVE), as all of the AVE values are larger than the recommended 
value of 0.5 , the convergent validity was confirmed. Lastly, the discriminant validity was tested by using Fornell \& Larcker (1981) criterion, with the AVE square roots larger than the corresponding correlations (Hair et al., 2014).

\section{Structural model}

We used SmartPLS v3.28 (Ringle et al., 2015) with the 5,000bootstrap procedure to test the hypotheses in our research model. The results of the structural model are presented in Figure 2. The hypotheses were tested by examining the $t$-values, $p$ values, standardized coefficient beta values and coefficient of determination $\left(\mathrm{R}^{2}\right.$ value). A hypothesis was accepted when the $t$-value was larger than critical value (i.e. $t \geq 1.96, p \leq .05$ ), using a two-tailed test.

As presented in Figure 2, the results support three of the five hypotheses, whereas the remaining two hypotheses are marginally accepted. Regarding the antecedents of perceived usefulness, the impact of perceived irreplaceability on perceived usefulness was the strongest $(\beta=.437, p<.001)$, followed by perceived convenience $(\beta=.205, p<.05)$, supporting $\mathrm{H} 2$ and H3. Additionally, the impact of perceived credibility on perceived usefulness is strong and marginally significant $(\beta=.227, p<.10)$. Thus, $\mathrm{H} 4$ was marginally accepted. Regarding the antecedents of adoption intention, the impact of perceived usefulness on adoption intention was strong and significant $(\beta=.728, p<.001)$, supporting H1. Finally, the impact of health belief on adoption intention was marginally significant ( $\beta=.126, p<.10)$. Therefore, H5 was marginally supported.

We also evaluate the explanatory power of the research model by assessing the $\mathrm{R}^{2}$ values (see Figure 2 ). The $\mathrm{R}^{2}$ values for perceived usefulness and adoption intention are .65 and .68 respec- tively. This highlights that the exogenous constructs are explaining $65 \%$ and $68 \%$ amount of variation in perceived usefulness and adoption intention respectively. In short, as the $\mathrm{R}^{2}$ values exceed the recommended criterion benchmark (i.e. >.10), the results suggest that the research model is explaining a meaningful amount of variation in the endogenous variables in line with Chin, 1998.

Furthermore, the results also presented the indirect effects of the exogenous variables, including perceived convenience, perceived credibility and perceived irreplaceability on adoption. In particular, the indirect effects of perceived irreplaceability $(\beta=.318, p<.001)$ and perceived convenience $(\beta=.149, p<.05)$ on

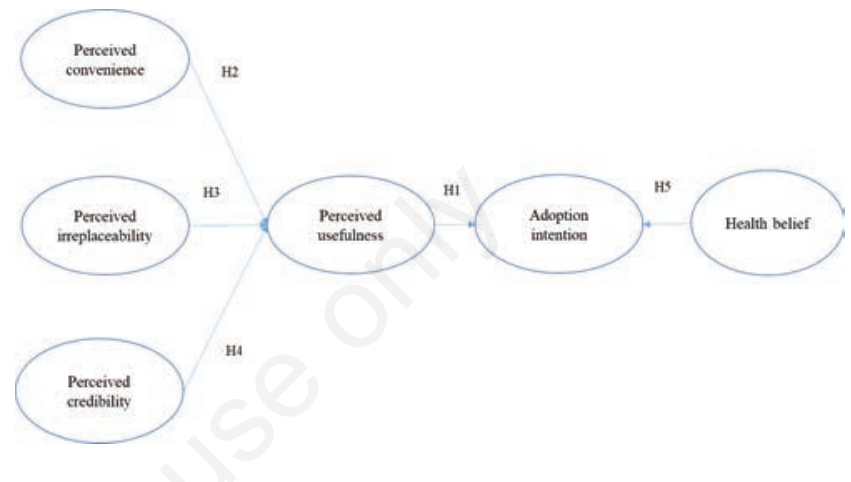

Figure 1. Research model.

\section{Table 1. Outer model results.}

\begin{tabular}{|c|c|c|c|c|}
\hline Construct & Loading & t-value & Alpha & $\begin{array}{l}\text { Composite } \\
\text { reliability }\end{array}$ \\
\hline $\begin{array}{l}\text { Perceived convenience } \\
\text { Learning to use the healthcare wearable device would be easy for me } \\
\text { My interaction with the healthcare wearable device would be clear and understandable } \\
\text { It would be easy for me to become skillful at using the healthcare wearable device } \\
\text { I think the healthcare wearable device is easy to carry } \\
\text { I have access to the healthcare wearable device anytime } \\
\text { I have access to the healthcare wearable device everywhere }\end{array}$ & $\begin{array}{l}.865 \\
.927 \\
.919 \\
.882 \\
.926 \\
.888\end{array}$ & $\begin{array}{l}39.104 \\
64.858 \\
61.013 \\
36.827 \\
82.358 \\
42.131\end{array}$ & .954 & .963 \\
\hline $\begin{array}{l}\text { Perceived irreplaceability } \\
\text { I think the healthcare wearable devices are superior to similar traditional devices } \\
\text { I think similar traditional devices, can't complete some functional tasks as the healthcare wearable devices do } \\
\text { I think there are some functional differences between the healthcare wearable devices and similar traditional devices }\end{array}$ & $\begin{array}{l}.917 \\
.897 \\
.865\end{array}$ & $\begin{array}{l}68.715 \\
40.342 \\
28.221\end{array}$ & .874 & .922 \\
\hline $\begin{array}{l}\text { Perceived credibility } \\
\text { The data provided by the healthcare wearable device are in line with my personal health data } \\
\text { I would find the software system of the healthcare wearable device credible } \\
\text { An adequate protection of my personal health information would make it more possible for me to use the healthcare wearable devi } \\
\text { It is more possible for me to use the healthcare wearable device if my personal health information will be protected }\end{array}$ & $\begin{array}{r}.910 \\
.889 \\
\text { vice } .899 \\
.888\end{array}$ & $\begin{array}{c}65.326 \\
31.882 \\
39.556 \\
43.89\end{array}$ & .919 & .943 \\
\hline $\begin{array}{l}\text { Health belief } \\
\text { I realize that bad living habits will cause harm to my health } \\
\text { I perceive that bad living habits will cause harm to my health } \\
\text { I hope I can change my bad habits and thus to minimize damage to health } \\
\text { I think I can improve my health status effectively in many ways like sports }\end{array}$ & $\begin{array}{l}.855 \\
.834 \\
.885 \\
.833\end{array}$ & $\begin{array}{r}32.283 \\
23.158 \\
37.857 \\
25.73\end{array}$ & .874 & .914 \\
\hline $\begin{array}{l}\text { Perceived usefulness } \\
\text { Using the healthcare wearable device would be useful in my personal health management } \\
\text { Using the healthcare wearable device would help me develop healthy habits } \\
\text { Using the healthcare wearable device would help me maintain healthy status }\end{array}$ & $\begin{array}{l}.927 \\
.939 \\
.932\end{array}$ & $\begin{array}{l}70.408 \\
71.722 \\
76.614\end{array}$ & .925 & .952 \\
\hline $\begin{array}{l}\text { Adoption intention } \\
\text { I am interested in using the healthcare wearable device } \\
\text { I plan to adopt the healthcare wearable device in the future } \\
\text { I will develop healthy habits with the healthcare wearable device in the future }\end{array}$ & $\begin{array}{l}.947 \\
.942 \\
.942\end{array}$ & $\begin{array}{l}111.282 \\
49.905 \\
82.584\end{array}$ & .938 & .960 \\
\hline
\end{tabular}


adoption intention were strong and significant, whilst the indirect effects of perceived credibility $(\beta=.165, p<.10)$ on adoption intention was marginally significant.

\section{Discussion}

\section{Theoretical implications}

This study contributes to the academic literature in several ways. First, to our knowledge this is one of the first study to explore on the impact of consumers' perceptions, including perceived irreplaceability, perceived convenience and perceived credibility on perceived usefulness and adoption intention of healthcare wearable technology products. Indeed, despite tremendous research undertaken in the area of the development of healthcare wearable technology, limited studies have focused on the antecedents of its adoption intention, especially for the association between health belief and adoption intention of healthcare wearable technology (Chuah et al., 2016; Marakhimov \& Joo, 2017; Zhang et al., 2017). This study has addressed this important gap by demonstrating the impact of technical attributes, including consumers' perceived irreplaceability, perceived convenience and perceived credibility in strengthening the adoption intention.

Second, this study contributes to the existing literature by demonstrating the relative importance of various technical attributes on perceived usefulness and adoption intention of healthcare wearable technology. In particular, the impact of perceived irreplaceability was the strongest, followed by perceived convenience and perceived credibility, revealing that irreplaceability, convenience and credibility should be taken into account when developing healthcare wearable technology products. Third, the results of this study revealed that consumers' perceived usefulness plays a considerable role in strengthening their adoption intention of healthcare wearable technology, confirming the findings of previous studies in similar areas (e.g., Chuah et al., 2016).

Finally, this study integrated the health belief in the research model, demonstrating the role of consumers' health belief on the adoption intention of healthcare wearable technology. Particularly, the results present that consumers' health belief has marginally significant impact on adoption intention of healthcare wearable technology, revealing the importance of considering the ways of strengthening consumers' health belief when developing the marketing strategies for healthcare wearable technology.

\section{Managerial implications}

There are several managerial implications from the results of this study. First, for developers of healthcare wearable technology, they are recommended to consider how to improve the technical attributes, including perceived irreplaceably, perceived convenience and perceived credibility of healthcare wearable technology in their research and development process. In particular, developers should consider how to improve the technological advantages of healthcare wearable technology by upgrading their hardware and software systems to improve the perceived convenience and perceived irreplaceably (Zhang et al., 2017). In addition, developers are also recommended to improve the software system in order to better protect the privacy of data related to users' health status, which is useful in improving the perceived credibility.

Additionally, product developers are recommended to focus on adding unique functions or favourable designs on healthcare wearable technology products in order to improve its irreplaceability. In particular, developers are recommended to upgrade the functions to enhance the uniqueness of healthcare wearable technology products, including the continuous improvement in big data analytics related to healthcare done by healthcare wearable technology (Wu et al., 2016), merging fashion to increase its prominence (Chuah et $a l ., 2016)$ and integrating advanced medical benefits to the healthcare wearable technology (Gao et al., 2015). The aforementioned initiatives are deemed to be effective in strengthening the perceived irreplaceability of healthcare wearable technology, which in turn strengthen its perceived usefulness and adoption intention.

Marketers should communicate the effectiveness of healthcare wearable technology in improving consumers' health, whilst addressing health concerns. This can contribute to improved user understanding of health, and potential usefulness of healthcare wearable technology.

\section{Limitation and directions for future research}

Although this study provides meaningful findings about antecedents of consumers' adoption of healthcare wearable technology, some limitations persist, providing directions for future research. First, this study has been conducted in Hong Kong, limiting its generalizability on a global scale. Future research should replicate this study in other countries, as well as comparisons between more countries with diverse cultures and different levels of economic. Second, this study was cross-sectional, and therefore cause and effect cannot be established. Future research should consider the implementation of longitudinal studies to compare consumers' adoption intentions in different time periods. Third, despite constructs of multiple perspectives are considered in the examining of consumers' adoption intention of healthcare wearable technology, some possible factors have been omitted. For

Table 2. Construct correlation matrix and AVE.

\begin{tabular}{lllllllll} 
& V1 & V2 & V3 & V4 & V5 & V6 & AVE Square root of AVE \\
Perceived convenience & 1 & & & & & .813 & .902 \\
Perceived irreplaceability & .792 & 1 & & & & .798 & .893 \\
\hline Perceived credibility & .868 .839 & 1 & & & .804 & .897 \\
Health belief & .553 .636 .597 & 1 & & & .726 & .852 \\
\hline Perceived usefulness & .748 .790 .771 .593 & 1 & & .870 & .933 \\
Adoption intention & .943 .735 .789 .557 & .802 & 1 & .890 & .943 \\
\hline
\end{tabular}

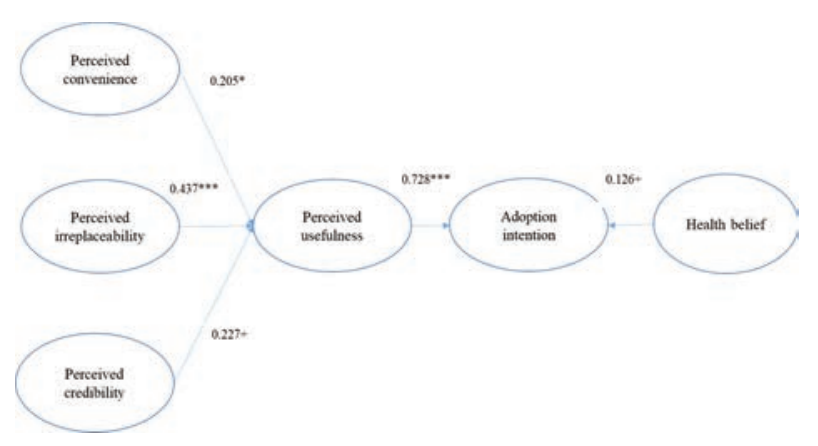

Figure 2. Results of the research model. Paths significant at + $\mathbf{p}<.10,{ }^{*} \mathbf{p}<.05,{ }^{* *} \mathbf{p}<.01,{ }^{* * *} \mathbf{p}<.001$. 
instance, online advertisements, electronic word of mouth available on the internet and the design of healthcare wearable technology products which can impact users understanding and knowledge of products and health more generally (Cheung et al., 2019). Thus, future research should consider integrating these possible factors in the research model to enhance its explaining power. Finally, some possible moderators have been omitted in this study such as the moderation effects of gender, usage experience, education level and income of consumers. Future research should examine the moderating effects of the aforementioned variables in the research model to enhance the explaining power of the study.

\section{Conclusions}

With the promising development of healthcare wearable technology industry, understanding of consumers' perceptions of, and adoption intention of, healthcare wearable technology products is an important step to better understand usage of healthcare wearable technology, which is meaningful in improving healthcare efficiency and reducing healthcare cost. This study sheds new light on understanding the formation of users' adoption intention in the context of healthcare wearable technology products, providing insights for developers and managers to conduct better business development strategies to strengthen users' adoption intention of healthcare wearable technology products.

\section{References}

Ahlan, A.R., \& Ahmad, B.I.E. (2014). User acceptance of health information technology (HIT) in developing countries: A conceptual model. Procedia Technology, 16, 1287-1296.

Ariff, M.S.M., Yeow, S.M., Zakuan, N., \& Bahari, A.Z. (2013). Acceptance of Internet Banking Systems among Young Managers. In IOP Conference Series: Materials Science and Engineering (Vol. 46, No. 1, p. 012024). IOP Publishing.

Ayeh, J.K. (2015). Travellers' acceptance of consumer-generated media: An integrated model of technology acceptance and source credibility theories. Computers in Human Behavior, 48 , 173-180.

Bagozzi, R.P. (2007). The legacy of the technology acceptance model and a proposal for a paradigm shift. Journal of the association for information systems, 8(4), 3 .

Benbasat, I., \& Barki, H. (2007). Quo vadis TAM?. Journal of the association for information systems, 8(4), 7.

Berry, L.L., Seiders, K., \& Grewal, D. (2002). Understanding service convenience. Journal of marketing, 66(3), 1-17.

Champion, V.L., \& Skinner, C.S. (2008). The health belief model. Health behavior and health education: Theory, research, and practice, 4, 45-65.

Chan, M., Estève, D., Fourniols, J.Y., Escriba, C., \& Campo, E. (2012). Smart wearable systems: Current status and future challenges. Artificial intelligence in medicine, 56(3), 137-156.

Cheung, M.L., Pires, G.D. \& Rosenberger III, P.J. (2019). Developing a conceptual Model for examining social media marketing effects on brand awareness and brand image. International Journal of Economics and Business Research, 17(3), 243-261.

Chin, W. (1998). The partial least squares approach for structural equation modelling. In G. Marcoulides (Ed.), Modern Methods for Business Research (pp. 295-336). Mahwah, NJ: Laurence
Erlbaum Associates.

Choi, G., \& Chung, H. (2013). Applying the technology acceptance model to social networking sites (SNS): Impact of subjective norm and social capital on the acceptance of SNS. International Journal of Human-Computer Interaction, 29(10), 619-628.

Choi, J., \& Kim, S. (2016). Is the smartwatch an IT product or a fashion product? A study on factors affecting the intention to use smartwatches. Computers in Human Behavior, 63, 777786.

Chuah, S.H.W., Rauschnabel, P.A., Krey, N., Nguyen, B., Ramayah, T., \& Lade, S. (2016). Wearable technologies: The role of usefulness and visibility in smartwatch adoption. Computers in Human Behavior, 65, 276-284.

Davis, F.D. (1989). Perceived usefulness, perceived ease of use, and user acceptance of information technology. MIS quarterly, 319-340.

Due, B.L. (2014). The future of smart glasses: An essay about challenges and possibilities with smart glasses. Working papers on interaction and communication, 1(2), 1-21.

Featherman, M.S., Miyazaki, A.D., \& Sprott, D.E. (2010). Reducing online privacy risk to facilitate e-service adoption: the influence of perceived ease of use and corporate credibility. Journal of Services Marketing, 24(3), 219-229.

Gao, Y., Li, H., \& Luo, Y. (2015). An empirical study of wearable technology acceptance in healthcare. Industrial Management \& Data Systems, 115(9), 1704-1723.

Gong, X., Zhang, K.Z., Cheung, C.M., Chen, C., \& Lee, M.K. (2019). Alone or Together? Exploring the Role of Desire for Online Group Gaming in Players' Social Game Addiction. Information \& Management.

HealthWorks Collective (2018). Wearable Tech Market Set for Significant Growth. Retrieved December 26, 2018, from https://www.medtechimpact.com/wearable-tech-market-setfor-significant-growth/

Holden, R.J., \& Karsh, B.T. (2010). The technology acceptance model: its past and its future in health care. Journal of biomedical informatics, 43(1), 159-172.

Hur, Y., Ko, Y.J., \& Claussen, C.L. (2012). Determinants of using sports web portals: An empirical examination of the sport website acceptance model. International Journal of Sports Marketing and Sponsorship, 13(3), 6-25.

Indu, R., \& Jagathy Raj, V.P. (2012). Developing a theoretical framework for a study on the impact of advertising credibility of consumer healthcare products. European Journal of Commerce and Management Research, 1(1), 14-24.

Jeong, S.C., Kim, S.H., Park, J.Y., \& Choi, B. (2017). Domain-specific innovativeness and new product adoption: A case of wearable devices. Telematics and Informatics, 34(5), 399-412.

Kalantari, M. (2017). Consumers' adoption of wearable technologies: literature review, synthesis, and future research agenda. International Journal of Technology Marketing, 12(3), 274-307.

Kawakami, T., \& Parry, M.E. (2013). The impact of word of mouth sources on the perceived usefulness of an innovation. Journal of Product Innovation Management, 30(6), 1112-1127.

Kim, H.W., Chan, H.C., \& Gupta, S. (2007). Value-based adoption of mobile internet: an empirical investigation. Decision support systems, 43(1), 111-126.

Kim, K.J., \& Shin, D.H. (2015). An acceptance model for smart watches: Implications for the adoption of future wearable technology. Internet Research, 25(4), 527-541.

Knight, H.M., Gajendragadkar, P.R., \& Bokhari, A. (2015). 
Wearable technology: using Google Glass as a teaching tool. BMJ case reports, 2015 , bcr2014208768.

Korenkova, M., \& Hägerfors, A. (2011, January). Quality criteria for digital information in long-term digital preservation. In Archiving Conference (Vol. 2011, No. 1, pp. 34-39). Society for Imaging Science and Technology.

Lee, J., Kim, D., Ryoo, H.Y., \& Shin, B.S. (2016). Sustainable wearables: wearable technology for enhancing the quality of human life. Sustainability, 8(5), 466.

Legris, P., Ingham, J., \& Collerette, P. (2003). Why do people use information technology? A critical review of the technology acceptance model. Information \& management, 40(3), 191204.

Li, H., Wu, J., Gao, Y., \& Shi, Y. (2016). Examining individuals' adoption of healthcare wearable devices: An empirical study from privacy calculus perspective. International journal of medical informatics, 88, 8-17.

Marakhimov, A., \& Joo, J. (2017). Consumer adaptation and infusion of wearable devices for healthcare. Computers in Human Behavior, 76, 135-148.

MedTech Impact of Wellness (2018). Forces Driving The Growth Of Wearable Medical Device Market. Retrieved December 26, 2018, from: https:/www.healthworkscollective.com/forcesdriving-the-growth-of-wearable-medical-device-market/

Metzger, M.J., Flanagin, A.J., \& Zwarun, L. (2003). College student Web use, perceptions of information credibility, and verification behavior. Computers \& Education, 41(3), 271-290.

Nasir, S., \& Yurder, Y. (2015). Consumers' and physicians' perceptions about high tech wearable health products. ProcediaSocial and Behavioral Sciences, 195, 1261-1267.

Ooi, K.B., \& Tan, G.W.H. (2016). Mobile technology acceptance model: An investigation using mobile users to explore smartphone credit card. Expert Systems with Applications, 59, 3346.

Özkan, T., Lajunen, T., Doğruyol, B., Yıldırım, Z., \& Çoymak, A. (2012). Motorcycle accidents, rider behaviour, and psychological models. Accident Analysis \& Prevention, 49, 124-132.

Pai, F.Y., \& Huang, K.I. (2011). Applying the technology acceptance model to the introduction of healthcare information systems. Technological Forecasting and Social Change, 78(4), 650-660.

Pedeliento, G., Andreini, D., Bergamaschi, M., \& Salo, J. (2016). Brand and product attachment in an industrial context: The effects on brand loyalty. Industrial Marketing Management, 53, 194-206.

Pikkarainen, T., Pikkarainen, K., Karjaluoto, H., \& Pahnila, S. (2004). Consumer acceptance of online banking: an extension of the technology acceptance model. Internet research, 14(3), 224-235.

Pradhan, D., Duraipandian, I., \& Sethi, D. (2016). Celebrity endorsement: How celebrity-brand-user personality congruence affects brand attitude and purchase intention. Journal of Marketing Communications, 22(5), 456-473.

Read, W., Robertson, N., \& McQuilken, L. (2011). A novel romance: the technology acceptance model with emotional attachment. Australasian Marketing Journal (AMJ), 19(4), 223-229.

Ross, T.P., Ross, L.T., Rahman, A., \& Cataldo, S. (2010). The bicy- cle helmet attitudes scale: using the health belief model to predict helmet use among undergraduates. Journal of American College Health, 59(1), 29-36.

Schifferstein, H.N., \& Zwartkruis-Pelgrim, E.P. (2008). Consumer-product attachment: Measurement and design implications. International journal of design, 2(3).

Shaw, N. (2014). The mediating influence of trust in the adoption of the mobile wallet. Journal of Retailing and Consumer Services, 21(4), 449-459.

Shin, D.H. (2009). Towards an understanding of the consumer acceptance of mobile wallet. Computers in Human Behavior, 25(6), 1343-1354.

Shin, D.H., Lee, S., \& Hwang, Y. (2017). How do credibility and utility play in the user experience of health informatics services?. Computers in Human Behavior, 67, 292-302.

Signorini, M.G., Fanelli, A., \& Magenes, G. (2014). Monitoring fetal heart rate during pregnancy: contributions from advanced signal processing and wearable technology. Computational and mathematical methods in medicine, 2014.

Tehrani, K., \& Michael, A. (2014). Wearable technology and wearable devices: Everything you need to know. Wearable Devices Magazine.

Ukpabi, D.C., \& Karjaluoto, H. (2017). Consumers' acceptance of information and communications technology in tourism: A review. Telematics and Informatics, 34(5), 618-644.

Wang, B.R., Park, J.Y., Chung, K., \& Choi, I.Y. (2014). Influential factors of smart health users according to usage experience and intention to use. Wireless personal communications, 79(4), 2671-2683.

Wang, C., Lee, M.K., \& Hua, Z. (2015). A theory of social media dependence: Evidence from microblog users. Decision Support Systems, 69, 40-49.

Wang, Y.S., Wang, Y.M., Lin, H.H., \& Tang, T.I. (2003). Determinants of user acceptance of Internet banking: an empirical study. International journal of service industry management, 14(5), 501-519.

Wu, B., \& Chen, X. (2017). Continuance intention to use MOOCs: Integrating the technology acceptance model (TAM) and task technology fit (TTF) model. Computers in Human Behavior, 67, 221-232.

Wu, J.H., \& Wang, S.C. (2005). What drives mobile commerce?: An empirical evaluation of the revised technology acceptance model. Information \& management, 42(5), 719-729.

Wu, J., Li, H., Cheng, S., \& Lin, Z. (2016). The promising future of healthcare services: When big data analytics meets wearable technology. Information \& Management, 53(8), 1020-1033.

Yoon, C., \& Kim, S. (2007). Convenience and TAM in a ubiquitous computing environment: The case of wireless LAN. Electronic Commerce Research and Applications, 6(1), 102112.

Zhang, M., Luo, M., Nie, R., \& Zhang, Y. (2017). Technical attributes, health attribute, consumer attributes and their roles in adoption intention of healthcare wearable technology. International journal of medical informatics, 108, 97-109.

Zhou, T., Lu, Y., \& Wang, B. (2010). Integrating TTF and UTAUT to explain mobile banking user adoption. Computers in human behavior, 26(4), 760-767. 